\title{
DIAGNÓSTICO SOBRE PRÁTICA DE EDUCAÇÃO AMBIENTAL EM UNIDADES DE CONSERVAÇÃO NO ESTADO DO PARANÁ
}

Carlos Henrique Gonçalves Luz ${ }^{1}$

Ana Lucia Suriani Affonso²

Resumo: A sociedade atual modificou-se em grande escala pelo desenvolvimento tecnológico e industrial e, cada vez mais, são vivenciados conflitos socioambientais. A Educação Ambiental (EA) surgiu na década de 1960 visando articular esses desafios socioambientais e explicitando possíveis mudanças nas ações humanas para a manutenção do meio em que estamos inseridos. O objetivo deste trabalho foi realizar uma revisão de literatura buscando diagnosticar como a EA está sendo praticada em Unidades de Conservação (UC) no estado do Paraná e se esta prática se associa a vertente conservadora ou crítica emancipatória. Espera-se assim, com a tessitura desse estudo teórico contribuir com a literatura sobre EA e, principalmente, diferenciar as vertentes Conservadora e Crítica. Para essa pesquisa, utilizou-se sites de busca de artigos científicos e a pesquisa booleana. Foram verificados somente trabalhos realizados em UCs que utilizaram a EA conservadora. Dessa forma, constatou-se que o objetivo dos trabalhos se resumia apenas a conduzir o público (visitantes) a uma reflexão sobre o ambiente, caracterizando ações distintas dos pressupostos da EA crítica, ou seja, pontuais, reducionistas, fragmentadas e unilateral da questão ambiental.

Palavras-chave: Educação Transformadora; Educação Conservadora; Áreas Preservadas.

\footnotetext{
${ }^{1}$ Universidade Estadual do Centro - UNICENTRO, E-mail: carlshenri1@gmail.com.

2 Universidade Estadual do Centro Oeste - UNICENTRO, Guarapuava, PR.

E-mail: analuciabio@gmail.com.
}

Revista brasileira educação ambiental 
Abstract: Today's society has changed on a large scale due to technological and industrial development, and, increasingly, socio-environmental conflicts experienced. Environmental Education (EE) emerged in the 60's aiming to articulate these socio-environmental challenges and explaining possible changes in human actions to maintain the environment in which we operate. The objective of this job was to do a literature review and diagnose how Environmental Education is practiced in Conservation Units (CU) in the state of Paraná. Furthermore, if this practice is associated with conservative or emancipatory criticism, it is expected with the weaving of this theoretical study contributes to the literature on Environmental Education. Moreover, differentiate the Conservative and Critical aspects. For this research, scientific articles search sites and Boolean research were used. Only works carried out in CU that used conservative EE were verified. Thus, it was found that the objective of the works was limited only to lead the public (visitors) to a reflection on the environment, characterizing actions different from the assumptions of critical $E E$, that is, punctual, reductionist, fragmented and unilateral of the environmental issue.

Keywords: Transformative Education; Conservative Education; Preserved Areas.

\section{Introdução}

A Educação Ambiental (EA) surgiu na década de 60 para 0 enfrentamento das questões de degradação do meio ambiente (TANNOUS; GARCIA, 2008). Para Loureiro (2007), a EA crítica vem a ser um processo político, crítico que objetiva a construção de sociedades sustentáveis. Assim, ela busca articular vertentes com a função de descobrir a causa do determinante de ordem ambiental e ao mesmo tempo promover a transformação das relações sociais que geram os impactos socioambientais.

Segundo a Lei no 9.795/1999, podemos definir EA como:

Art. $1^{\circ}$ Entendem-se por Educação Ambiental os processos por meio dos quais o indivíduo e a coletividade constroem valores sociais, conhecimentos, habilidades, atitudes e competências voltadas para a conservação do meio ambiente, bem de uso comum do povo, essencial à sadia qualidade de vida e sua sustentabilidade. (BRASIL, 1999, p.1).

A questão ambiental e a educação são políticas eminentes e implicam explicitamente no construir, necessitando da ação transformadora no ambiente em que estamos inseridos, por meio da participação responsável de sujeitos da sociedade. Assim, a EA crítica funciona como um processo educativo que tematiza a relação sociedade e natureza, evidenciando os determinantes 
causais da crise socioambiental atual, suas consequências e possíveis enfrentamentos (LOUREIRO, 2007).

A EA tratada dentro do contexto escolar é designada na Política Nacional de EA (BRASIL, 1999, p.1) no que se refere o artigo $2^{\circ}$ "a Educação Ambiental é um componente essencial e permanente na educação nacional, devendo estar presente de forma articulada, em todos os níveis e modalidades do processo educativo, em caráter formal e não-formal". Assim, entende-se que a EA deve funcionar de forma transversal e interdisciplinar inerente à prática das disciplinas.

A Resolução №2, de 18 de junho de 2012, estabelece as Diretrizes Curriculares Nacionais para a EA, instituída com base na LEI 9.795/99, aborda a temática da EA crítica como uns dos principais objetivos como está definido no Artigo 1ำ parágrafo II:

II - estimular a reflexão crítica e propositiva da inserção da Educação Ambiental na formulação, execução e avaliação dos projetos institucionais e pedagógicos das instituições de ensino, para que a concepção de Educação Ambiental como integrante do currículo supere a mera distribuição do tema pelos demais componentes. (BRASIL, 2012, p. 2).

Para Adams (2012) entende-se que essa resolução por meio da EA crítica define os objetivos para que docentes aprimorem sua práxis de maneira interdisciplinar em todos os níveis educacionais e que cada vez mais sejam elaborados projetos de forma continuada levando a criticidade aos seus educandos referente a parte ambiental, social, política, cultural e educacional, mudando os preceitos de trabalhos que apenas são tratados de forma pontual e reflexiva, como exemplo temos o dia da água, dia da terra e semana do meio ambiente, abordagens essas trabalhadas por meio da EA conservadora.

Lima (2002) explicita que a tendência conservadora resguarda a estrutura social, mantendo suas características com seus valores culturais, políticos e econômicos. Loureiro (2004) exemplifica que a tendência crítica transformadora tem o propósito da transformação social, renovando-a em relação ao meio ambiente. Assim, pode-se evidenciar a EA em duas tendências como mostra o Quadro 1: 
Quadro 1: Análises entre a EA Conservadora e EA Crítica Emancipatória:

\begin{tabular}{|c|c|}
\hline $\begin{array}{l}\text { EDUCAÇÃO AMBIENTAL } \\
\text { CONSERVADORA }\end{array}$ & $\begin{array}{c}\text { EDUCAÇÃO AMBIENTAL CRÍTICA } \\
\text { EMANCIPATÓRIA }\end{array}$ \\
\hline $\begin{array}{l}\text { Lima (2002, p. 127) caracteriza a } \\
\text { tendência de Educação Ambiental } \\
\text { conservadora como: } \\
\text { - Concepção reducionista, } \\
\text { fragmentada e unilateral da questão } \\
\text { ambiental; } \\
\text { - Compreensão naturalista e } \\
\text { conservacionista da crise ambiental; } \\
\text { - Tendência a sobrevalorizar as } \\
\text { respostas tecnológicas diante dos } \\
\text { desafios ambientais; } \\
\text { - Baixa incorporação de princípios e } \\
\text { práticas interdisciplinares; } \\
\text { - Separação entre as dimensões } \\
\text { sociais e naturais da problemática } \\
\text { ambiental; } \\
\text { - Banalização das noções de } \\
\text { cidadania e participação que na } \\
\text { prática são reduzidas a uma } \\
\text { concepção liberal, passiva e } \\
\text { disciplinar. }\end{array}$ & $\begin{array}{l}\text { A tendência transformadora, emancipatória } \\
\text { de Educação Ambiental (LIMA, 2002, p. } \\
\text { 128-129); (LOUREIRO, 2004, p. 32-33) é } \\
\text { caracterizada como: } \\
\text { - Atitude crítica diante dos desafios que a } \\
\text { crise civilizatória nos coloca, partindo-se } \\
\text { do princípio de que o modo como vivemos } \\
\text { não atende mais aos nossos anseios e } \\
\text { compreensão de mundo e sociedade e de } \\
\text { que é preciso criar novos caminhos; } \\
\text { - Preocupação concreta em estimular o } \\
\text { debate e o diálogo entre as ciências, } \\
\text { redefinindo objetos de estudo e saberes; } \\
\text { - Entendimento da democracia como } \\
\text { condição para a construção de uma } \\
\text { sustentabilidade substantiva; } \\
\text { - Convicção de que o exercício da } \\
\text { participação social e o exercício pleno da } \\
\text { cidadania são práticas indispensáveis à } \\
\text { democracia e à emancipação } \\
\text { socioambiental; } \\
\text { - Busca de ruptura e transformação dos } \\
\text { valores e práticas sociais contrários ao } \\
\text { bem-estar público e à equidade. }\end{array}$ \\
\hline
\end{tabular}

Fonte: Adaptado de Oliveira (2008).

Dessa forma, ao analisar as tendências ambientais de caráter conservador e reflexivo, entende-se que elas não garantem o rigor teórico, divergindo dos princípios da EA crítica, pois são representadas a partir de resultados da degradação ambiental, que de certo modo estão relacionadas a produção capitalista e ao crescimento populacional das últimas décadas.

Com isso, o objetivo deste trabalho foi realizar uma revisão de literatura buscando diagnosticar como a EA está sendo praticada em Unidades de Conservação (UCs) no estado do Paraná, e se esta prática se relaciona com a vertente conservadora ou crítica emancipatória.

\section{Metodologia}

Foi realizado em levantamento bibliográfico referente a artigos que abordavam a prática de EA em UCs nas esferas federal, estadual e municipal do estado do Paraná. Segundo Neves, Jankoski e Schnaider (2013) uma das formas de busca por artigos seria por meio de operadores booleanos, que relacionam dois uma mais elementos em uma busca, possibilitando três condições básicas de busca, "E", "OU" e "MENOS". Assim, a presente pesquisa 
utilizou as seguintes combinações: Educação Ambiental e Unidades de Conservação no Paraná; Educação Ambiental ou Unidade de Conservação no Paraná; Educação Ambiental menos Unidades de Conservação no Paraná. Os resultados dessa busca encontram-se no Quadro 2 abaixo.

Quadro 2: Número de resultados obtidos a partir da busca realizada por pesquisa booleana.

\begin{tabular}{|c|c|}
\hline TERMOS PESQUISADOS & NÚMERO DE RESULTADOS OBTIDOS \\
\hline $\begin{array}{c}\text { Educação Ambiental e unidades de } \\
\text { conservação no Paraná }\end{array}$ & 2.940 .000 \\
\hline $\begin{array}{c}\text { Educação Ambiental ou unidades de } \\
\text { conservação no Paraná }\end{array}$ & 5.960 .000 \\
\hline $\begin{array}{c}\text { Educação Ambiental menos unidades de } \\
\text { conservação no Paraná }\end{array}$ & 4.960 .000 \\
\hline
\end{tabular}

Fonte: autoria própria.

A partir desse expediente metodológico, foram consultados os seguintes sites de buscas - PubMed, Web of Science e google acadêmico. Também foram analisados sites que continham informações sobre as UCs como o Instituto Ambiental do Paraná (IAP) e o Instituto Brasileiro do Meio Ambiente e dos Recursos Naturais Renováveis (IBAMA).

\section{Resultados e discussões}

As pesquisas e projetos de EA realizadas em UCs funcionam como um mediadores para desafios ocorrentes entre sociedade e o ambiente, sejam elas por meio da abordagem conservacionista, que ocorre de maneira informal e leva a reflexão diante das ações do homem sobre o meio ambiente (GUIMARÃES, 2007), ou pela abordagem crítica emancipatória, que traz a visão complexa do socioambientalismo, sendo assim, multidisciplinar com foco principal na compreensão e transformação da prática social (LOUREIRO, 2007).

Segundo IAP (2017), no Paraná as UCs estão presentes em 125 Municípios (31,3\% do total de 399 municípios) e são divididas em 14 categorias sendo ligadas à três esferas administrativas Federal, Estadual e Municipal (Figura 1). 


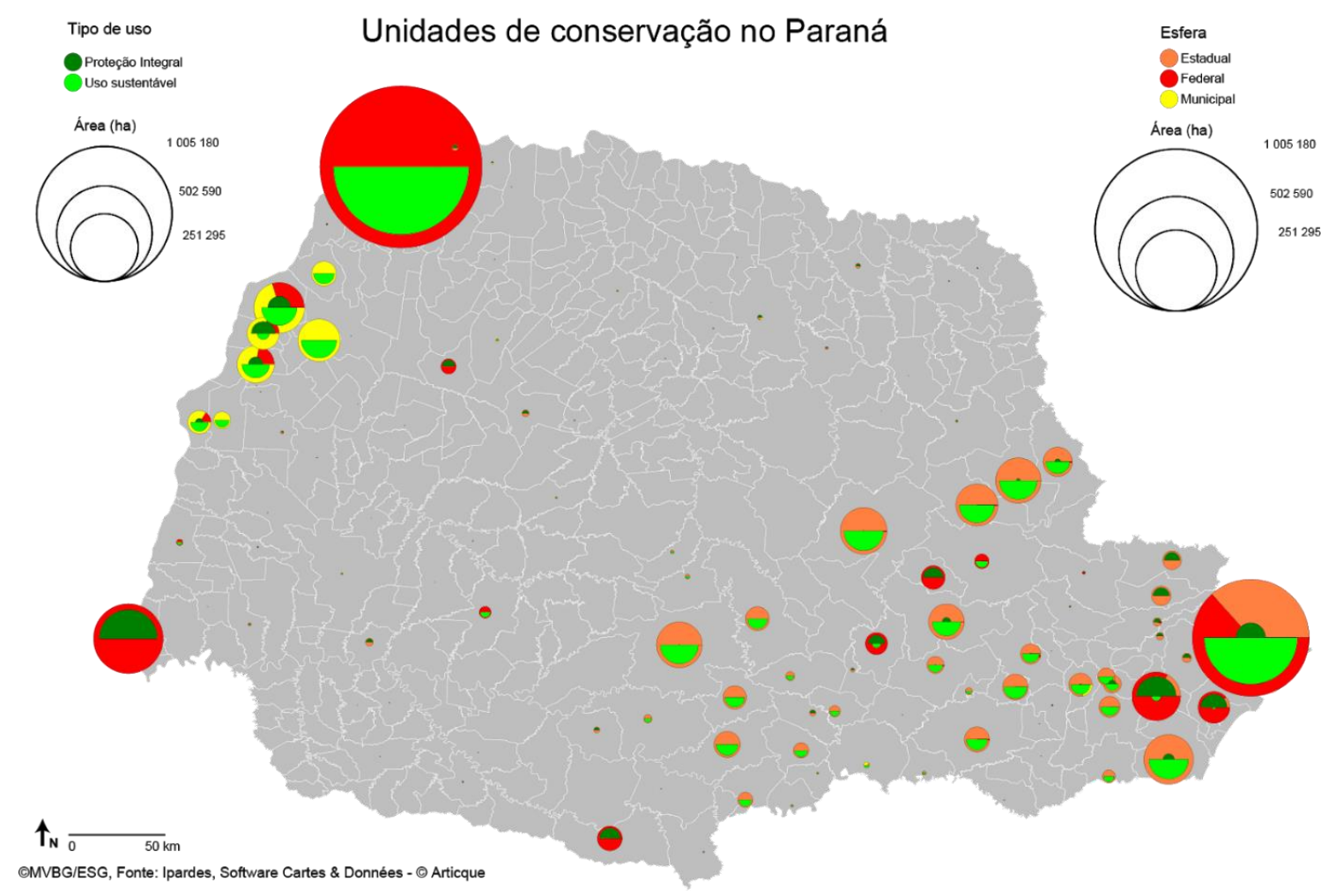

Figura 1: UCs no Paraná segundo grupos e esferas administrativas. Fonte: Confins (2016).

As áreas protegidas e de uso sustentável passam por desafios diários, sobre como levar para sociedade a importância de se ter áreas de proteção ambiental, por meio de ações que promovam a interação entre a sala de aula e as UCs, a partir de projetos de EA.

Segundo MMA (2020, p. 1) afirma que:

Para atingir esse objetivo de forma efetiva e eficiente, foi instituído o Sistema Nacional de Conservação da Natureza (SNUC), com a promulgação da Lei no 9.985 , de 18 de julho de 2000. A Lei do SNUC representou grandes avanços à criação e gestão das UC nas três esferas de governo (federal, estadual e municipal), pois ele possibilita uma visão de conjunto das áreas naturais a serem preservadas. Além disso, estabeleceu mecanismos que regulamentam a participação da sociedade na gestão das UC, potencializando a relação entre o Estado, os cidadãos e o meio ambiente. 
Tabela 1: UCs federais existentes no Paraná.

\begin{tabular}{|c|c|c|}
\hline DENOMINAÇÃO & ÁREA (ha) & MUNICÍPIOS \\
\hline APA das ilhas e Várzeas do Rio Paraná & $1.003 .059,00$ & $\begin{array}{l}\text { Diamante do Norte, Marilena, Nova } \\
\text { Londrina, Porto Rico, Querência do } \\
\text { Norte, São Pedro do Paraná }\end{array}$ \\
\hline APA de Guaraqueçaba & $291.498,00$ & Guaraqueçaba \\
\hline ARIE do Pinheiro Pinheirinho & 109,00 & Guaraqueçaba \\
\hline Estação Ecológica de Guaraqueçaba & $13.638,90$ & Guaraqueçaba \\
\hline Floresta Nacional de Irati & $3.495,00$ & Teixeira Soares, Fernandes Pinheiro \\
\hline Floresta Nacional do Açungui & 728,78 & Campo Largo \\
\hline Parque Nacional de Ilha Grande & $78.875,00$ & $\begin{array}{c}\text { Altônia, Guaíra, Icaraíma, São Jorge } \\
\text { do Patrocínio, Vila Alta }\end{array}$ \\
\hline Parque Nacional do Iguaçu & $185.262,50$ & $\begin{array}{l}\text { Céu Azul, Foz do Iguaçu, Matelândia, } \\
\text { Medianeira, São Miguel do Iguaçu }\end{array}$ \\
\hline Parque Nacional do Superagui & $34.254,00$ & Guaraqueçaba \\
\hline Parque Nacional Saint Hilaire-lange & $25.161,00$ & $\begin{array}{c}\text { Guaratuba, Morretes, Matinhos e } \\
\text { Alexandra }\end{array}$ \\
\hline
\end{tabular}

Fonte: IAP (2005).

Abaixo faremos um relato de como as UCs paranaenses trabalham a EA nas esferas Federal, Estadual e Municipal objetivando exemplificar a análise e os trabalhos registrados.

De acordo com as premissas das leis ambientais, no Parque Nacional do Iguaçu situado na Cidade de Foz do Iguaçu (PR), regulamentado pelo decreto-lei federal ํo 1.035 de 10 de janeiro de 1939, são desenvolvidas ações de EA por meio da interação reflexiva entre o homem e a natureza por trilhas interpretativas, passeios com variados meios de transportes e observação das belezas cênicas naturais, que contemplam essa UC na esfera federal (BRASIL, 2018).

O Parque Nacional da llha Grande (Parna llha Grande), abrange nove municípios: Altônia, Guaíra, Icaraíma, São Jorge do Patrocínio, Vila Alta no lado paranaense e Mundo Novo, Eldorado, Naviraí e Itaquiraí no lado matogrossense. O mesmo foi criado pelo projeto de lei do IAP em 1997 e desenvolvido pela IBAMA fazendo parte de um ecossistema integrando o corredor da biodiversidade do Rio Paraná (SANTOS, 2014). Ainda segundo a mesma autora, são poucas ou quase inexistente as práticas de EA no Paraná. Em 2014 foi realizada uma intervenção de práticas ambientais com a finalidade de conscientização da população ao redor e de visitantes, outro intuito do projeto foi aumentar o turismo ecológico da região, utilizando as trilhas do parque, sendo que "Nos percursos realizados pelas trilhas são elaborados formas de evidenciar a peculiaridade e os aspectos relevantes para a sensibilização quanto à questão ambiental e para o conhecimento natural do parque." (SANTOS, 2014, p. 32-33).

No Parque Estadual da Vila Velha em Ponta Grossa (PR), visando a proteção de formação de arenitos, uma UC estadual foi criado pela lei estadual no 1.292 de 12 de outubro de 1953. Esse parque propõe iniciativas por 
visitações de escolas e turistas, que percorrem as trilhas interpretativas, sendo o conhecimento passado de uma maneira reflexiva (PARANÁ, 2004).

Em Guarapuava o Parque Municipal Natural das Araucárias é regulamentado pela lei municipal 198/91 e abriga um remanescente de Floresta Ombrófila Mista. Nesse local, existem diversas maneiras de promover a aproximação entre a UC e escolas do município por meio de atividades de EA como palestras, trilhas interpretativas, cursos e eventos. A trilha noturna é uma das ações realizada neste Parque a partir de uma abordagem da EA conservadora, promove uma reflexão dos envolvidos sobre o meio em que estamos inseridos (GROFOSKI; LUZ.; MAZON, 2017).

Também corroborando para a prática da EA conservadora em UCs no Estado do Paraná, Carrillo e Biondi (2007, p. 116) relatam que por meio de atividades no Litoral Norte em Guaraqueçaba nas Ilha Rasa, Ilha das Peças, Ilha de Superagui e em Paranaguá nas Ilhas do mel e Valadares "Os módulos educativos foram compostos de atividades lúdico-didáticas, palestras e peça teatral, que tinham como tema central a conservação do papagaio-da-cararoxa." buscando levar os alunos a reflexão. Os autores acima também ressaltam que "a principal finalidade dessas atividades foi despertar a comoção dos participantes para a natureza", ações essas ligadas e EA conservadora.

Nesse mesmo contexto, Souza (2014, p. 247) em pesquisa de iniciação científica desenvolvida na Estação Ecológica do Caiuá-PR (ESEC- Caiuá), considera:

Que a Educação Ambiental e a possibilidade de sensibilização através do desenvolvimento de atividades no ambiente de trilhas ecológicas e/ou interpretativas e que a EA em conjunto ao ambiente da trilha aparece e se firma como metodologia impar em processos de sensibilização ambiental.

Dessa forma, pode-se perceber que os artigos publicados sobre práticas e ações de EA desenvolvidas em UCs são abordadas por meio da vertente conservacionista, a qual possui uma perspectiva crítica limitada ou inexistente, valorizando apenas a concepção emotiva e reflexiva dos seus integrantes e deixando de lado a criticidade e, principalmente, ações transformadoras do contexto socioambiental.

\section{Considerações finais}

Após as análises dos artigos conclui-se que nas três escalas das UCs (federais, estaduais e municipais) no estado do Paraná, foram verificadas práticas de EA caracterizadas como conservadoras, ou seja, explorando apenas uma reflexão do ser humano frente às observações de belezas naturais. Já a abordagem crítica transformadora de acordo com Loureiro e Layrargues (2013), é um processo educativo eminentemente político, que visa 
ao desenvolvimento nos educandos de uma consciência crítica acerca das instituições, atores e fatores sociais geradores de riscos e respectivos conflitos socioambientais. Busca uma estratégia pedagógica do enfrentamento de tais conflitos a partir de meios coletivos de exercício da cidadania, pautados na criação de demandas por políticas públicas participativas conforme requer a gestão ambiental democrática.

Portanto, destaca-se que as ações de EA em UCs caracterizam-se como fragmentadas e distante das proposições críticas, emancipadora, problematizadora e questionadora da EA transformadora. É necessário que as ações de EA em UCs abordem as relações ambientais, sociais, culturais, políticas e históricas dos locais, oportunizando a participação de todos nesse processo educacional.

\section{Referências}

ADAMS, B. G. A importância da lei 9.795/99 e das diretrizes curriculares nacionais da educação ambiental para docentes. REMOA/UFSM, Revista monografias ambientais, v. 10, n. 10, p. $2148-2157,2012$.

BRASIL. Lei Federal № 9.985, de 18 de julho de 2000. Regulamenta o art. 225, § 10, incisos I e II da Constituição Federal, institui o Sistema Nacional de Unidades de Conservação da Natureza e dá outras providências, 2000.

BRASIL. Lei № 9.795 de 27 de abril de 1999. Dispõe sobre a Educação Ambiental, institui a Política Nacional de Educação Ambiental e dá outras providências. Diário Oficial da República Federativa do Brasil, Brasília, n. 79, 28 abr. 1999.

BRASIL. Resolução № 2, de 18 de junho de 2012, que estabelece as Diretrizes Curriculares Nacionais para a Educação Ambiental. 2012.

CARILLO, A. C.; BATISTA, D, B. A conservação do papagaio-da-cara-roxa (Amazona brasiliensis) no estado do paraná - uma experiência de educação ambiental no ensino formal. Revista Árvore, Viçosa-MG, v.31, n.1, p.113-122, 2007.

CONFINS. Revue franco-brésilienne de géographie est mis à disposition selon les termes de la licence Creative Commons Attribution. Pas d'Utilisation Commerciale - Partage dans les Mêmes Conditions 4.0 International. 2016.

GROFOSKI, L. C.; LUZ, C. H. G.; MAZON, J. A. Idealização da trilha da lua cheia no Parque Municipal das Araucárias em Guarapuava (PR). Relato de experiência. XV Encontro Paranaense de Educação Ambiental, 2017.

GUIMARÃES, M. A Formação de Educadores Ambientais. $3^{a}$ ed. São Paulo: Papirus. 2007.

IAP. Instituto Ambiental do Paraná. 2005. Disponível em: <http://www.uc.pr.gov.br/> Acesso em: 05 de agosto de 2019.

Revista brasileira educação ambiental 
IAP. Instituto Ambiental do Paraná. 2017. Disponível em: <http://www.uc.pr.gov.br/> Acesso em: 05 de agosto de 2019.

LIMA, G. F. C. Crise ambiental, educação e cidadania: os desafios da sustentabilidade emancipatória. In: LOUREIRO, C. F. B. Educação Ambiental: repensando o espaço da cidadania. São Paulo: Cortez, 2002. p. 127-129.

LOUREIRO, C. F. B. Trajetória e fundamentos da Educação Ambiental. São Paulo: Cortez, 2004.

LOUREIRO, C. F. B. Educação Ambiental Crítica: contribuições e desafios. In: BRASIL. Vamos Cuidar do Brasil: Conceitos e práticas em Educação Ambiental na Escola. Ministério da Educação. Brasília. 2007. p.57-64.

LOUREIRO; C, F. B.; LAYRARGUES, P. P. Ecologia política, justiça e educação ambiental crítica: perspectivas de aliança contra-hegemônica. Trab. Educ. Saúde, Rio de Janeiro, v. 11 n. 1, p. 53-71. 2013.

MMA - Ministério do Meio Ambiente. Disponível em: $<$ https://www.mma.gov.br/areas-protegidas/unidades-de-conservacao >

Acesso: 09 de março de 2020.

MOREIRA, M. A. Aprendizagem significativa: a teoria e textos complementares. São Paulo: Livraria da Física, 2011.

NEVES, I. M.; JANKOSKI, D. A.; SCHNAIDER, M. J. (Orgs). Tutorial de pesquisa bibliográfica. Curitiba: SiBi/UFPR, 2013.

OLIVEIRA, M. L. Trabalho docente: por uma educação ambiental crítica, transformadora e emancipatória. GT-22: Educação Ambiental. Recife. 2008. Disponível em: <http://www.anped.org.br/sites/default/files/gt22-4916-int.pdf> Acesso em: 04 de agosto de 2019.

PARANÁ. Plano de Manejo Parque Estadual de Vila Velha. Instituto Ambiental do Paraná, Curitiba, 2004. Disponível em: $<$ http://www.iap.pr.gov.br/arquivos/File/Planos de Manejo/PE VilaVelha/PEVV introducao final.pdf> Acesso em: 06 de agosto de 2019.

SANTOS, D. R. V. Proposta de Programa de Educação Ambiental para o Parque Nacional de llha Grande: integrando proteção ambiental e participação social. 2014. 40f. Monografia (Especialização em Gestão Ambiental em Municípios). Universidade Tecnológica Federal do Paraná, Medianeira, 2014. Disponível em: <http://repositorio.roca.utfpr.edu.br/jspui/handle/1/6253.>. Acesso em: 06 de agosto de 2019.

SOUZA, M. C. C. Educação ambiental e as trilhas: contexto para a sensibilização ambiental. Revista Brasileira de Educação Ambiental, São Paulo, v. 9, n. 2, p. 239-253, 2014.

TANNOUS, S.; GARCIA, A. Histórico e evolução da Educação Ambiental, através dos tratados internacionais sobre o meio ambiente. Nucleus, v.5, n.2, p. 183-196. 2008. 